\title{
Retraction Note to: Effect of Metal Oxides on the Catalytic Activities of Sulfonated Graphene Oxide for the Esterification of Oleic Acid and Conversion of Waste Cooking Oil to Biodiesel
}

\author{
Reena D. Souza ${ }^{1,2} \cdot$ Tripti Vats $^{2} \cdot$ Amit Chattree $^{1} \cdot$ Prem Felix Siril $^{2}$ \\ Received: 1 June 2021 / Accepted: 7 June 2021 / Published online: 23 June 2021 \\ (c) Springer Science+Business Media, LLC, part of Springer Nature 2021
}

Retraction to: Catalysis Letters (2018) 148:2848-2855

https://doi.org/10.1007/s10562-018-2472-7

The Editors-in-Chief have retracted this article at the request of the corresponding author. Concerns were raised regarding some figures, specifically:

- Fig. 1a: the FT-IR spectrum for GO-ZnO-SO3H appears to be highly similar to the FT-IR spectrum for GO-CuO$\mathrm{SO} 3 \mathrm{H}$ in the same figure, particularly in the spectral noise.

- Fig. 1b: the FT-IR spectrum for GO-ZnO-SO3H appears to be highly similar to the FT-IR spectrum for GO-CuO-
$\mathrm{SO} 3 \mathrm{H}$ in the same figure, particularly in the spectral noise.

- Fig. 4 shows a number of irregularities.

Prem Felix Siril and Tripti Vats agree to this retraction. Reena D. Souza and Amit Chattree have not responded to correspondence regarding this retraction.

Publisher's Note Springer Nature remains neutral with regard to jurisdictional claims in published maps and institutional affiliations.

The original article can be found online at https://doi.org/10.1007/ s10562-018-2472-7.

Prem Felix Siril

prem@iitmandi.ac.in

1 SHUATS, Allahabad, Uttar Pradesh, India

2 School of Basic Sciences, Indian Institute of Technology Mandi, Mandi, Himachal Pradesh 175005, India 